\title{
The Effect of Preoperative Anxiety and Pain Sensitivity on Preoperative Hemodynamics, Propofol Consumption, and Postoperative Recovery and Pain in Endoscopic Ultrasonography
}

\author{
Ferda Yilmaz Inal (D) - Yadigar Yilmaz Camgoz · Hayrettin Daskaya • \\ Hasan Kocoglu
}

Received: June 11, 2021 / Accepted: July 9, 2021 / Published online: July 22, 2021

(c) The Author(s) 2021

\section{ABSTRACT}

Introduction: The present study investigates how preoperative anxiety and pain sensitivity affect the consumption of anesthetics, time elapsed until the desired sedation level is achieved, preoperative hemodynamics, postoperative recovery time, and postoperative pain.

Methods: The present study includes 80 ASA 1-2 patients aged between 20 and 65 who were scheduled for endoscopic ultrasonography (EUS) under sedation. Patients were instructed to fill out the Spielberger State-Trait Anxiety Inventory (STAI) and Pain Sensitivity Questionnaire (PSQ) before the procedure. For

F. Yilmaz Inal $(\bowtie) \cdot H$. Kocoglu

Department of Anaesthesiology and Reanimation, Faculty of Medicine, Istanbul Medeniyet University, Goztepe Prof. Dr. Suleyman Yalcin Sehir Hastanesi, Dr. Erkin Cad., Kadikoy, 34722 Istanbul, Turkey e-mail: ferdayilmazinal@hotmail.comH. Kocoglu e-mail: hasankocoglu@yahoo.com

Y. Yilmaz Camgoz

Clinic of Anaesthesiology and Reanimation, Sultan Abdülhamid Han Training and Research Hospital,

Selimiye mh, Tibbiye Cd, Uskudar, 34668 Istanbul, Turkey

e-mail: dryadigaryilmaz@gmail.com

\section{H. Daskaya}

Department of Anaesthesiology and Reanimation, Faculty of Medicine, Bezmialem Vakif University, Iskender Pasa Mh, Adnan Menderes Blv., Fatih, 34093 Istanbul, Turkey

e-mail: h.daskaya@gmail.com sedation, $0.03 \mathrm{mg} \mathrm{kg}^{-1}$ intravenous midazolam, $1 \mathrm{mg} \mathrm{kg}^{-1}$ lidocaine, $1 \mu \mathrm{kg}^{-1}$ fentanyl, and then a bolus dose of $1 \mathrm{mg} \mathrm{kg}^{-1}$ propofol were infused over a period of $60 \mathrm{~s}$. The time elapsed until the bispectral index (BIS) value reached 75 was recorded. For anesthesia maintenance, $2 \mathrm{mg} \mathrm{kg}^{-1} \mathrm{~h}^{-1}$ propofol infusion was administered. In the case of sedation failure, an additional dose of $0.1 \mathrm{mg} \mathrm{kg}^{-1}$ propofol (IV) was administered to ensure sedation depth with a BIS level of 65-75, and the propofol infusion was halted once the BIS value dropped below 65.

Results: STAI-S and STAI-T scores were significantly positively correlated with PSQ minor pain and PSQ total scores. The time elapsed until reaching a BIS level of 75, propofol infusion dose used during sedation, and the need for additional doses of propofol, heart rate (HR), and duration of post-anesthesia care unit stay were significantly positively correlated with both preoperative anxiety and preoperative pain sensitivity. In terms of postoperative pain, the visual analog scale (VAS) at $1 \mathrm{~h}$ was more highly correlated with STAI-S and STAI-T than with PSQ. The VAS $2 \mathrm{~h}$ was only correlated with STAI-S and STAI-T.

Conclusion: The significant linear correlation between preoperative anxiety and pain sensitivity and anesthesia need can facilitate better preoperative management by predicting individual anesthetic consumption. 
Trial Registration: The study was registered with the number NCT03114735 on ClinicalTrials.gov.

Keywords: Anesthetic consumption; Anxiety; Pain sensitivity; Sedoanalgesia

\section{Key Summary Points}

Psychological factors are considered to influence patients' anesthetic requirements and individual differences in postoperative pain, even in the same surgical procedures.

The effects of both anxiety and pain sensitivity were investigated in patients who underwent endoscopic ultrasonography with sedoanalgesia.

Preoperative anxiety and pain sensitivity were correlated with the time taken to reach the desired level of sedation, the need for preoperative anesthetic agents, postoperative recovery time, and postoperative pain severity.

This approach can facilitate better preoperative management by estimating individual anesthetic consumption.

\section{INTRODUCTION}

Psychological factors are considered to influence patients' anesthetic requirements and their individual differences in postoperative pain, even in the same surgical procedures [1-5]. One of these psychological factors, preoperative anxiety, has been investigated in many studies focusing on its effects on anesthetic consumption, preoperative hemodynamics, neuroendocrine response, postoperative pain, and analgesic consumption $[3,6-9]$. However, there are few data on the effects of pain sensitivity [5, 10-12]. Some studies have demonstrated that postoperative acute pain intensity can be estimated by detecting preoperative pain sensitivity $[5,13,14]$. However, there are no studies in which the effects of both anxiety and pain sensitivity have been investigated in patients undergoing endoscopic ultrasonography accompanied by sedoanalgesia. Self-rated pain sensitivity is evaluated with the Pain Sensitivity Questionnaire (PSQ), which gives similar results as experimental pain sensitivity assessment methods [15]. Spielberger's State-Trait Anxiety Inventory (STAI), one of the methods used in the measurement of anxiety, evaluates temporary and stable anxiety [16].

Endoscopic ultrasonography (EUS) is a method used for treatment and diagnostic purposes. Today, intravenous sedation is a standard practice in patients undergoing EUS [18-21]. It has a larger insertion tube compared to a standard endoscope since it is generally stiffer and greater in diameter and length. EUS is often more complicated than standard endoscopy and takes a longer time. Therefore, it requires medium-deep sedation for the comfort and assurance of the patient and the endoscopist. Prolonged sedation in high doses naturally may increase the risk of complications and the recovery time. The amount of anesthetic agents, anesthesia duration, and anesthetics used are important considerations for same-day patients so that they recover quickly and safely after the EUS procedure.

Therefore, this study aimed to evaluate the effects of preoperative anxiety and pain sensitivity, anesthetic consumption, time to reach desired sedation level, preoperative hemodynamics, postoperative recovery time, and postoperative pain in patients undergoing EUS.

\section{METHODS}

\section{Study Population}

The study included a total of 80 patients aged 20-65 years with ASA 1-2 scores on the American Society of Anesthesiologists (ASA) physical status classification and who were electively scheduled for EUS under sedation in the endoscopy unit. All EUS procedures included in the study were diagnostic. EUS requiring invasive 
procedures was excluded. The inclusion criteria were as follows: educational background and mental status sufficient to be able to fill out the scales and surveys intended for assessment, no psychiatric or neurological disorders, no use of psychiatric medications or alcohol consumption, and no significant cardiovascular, respiratory, or liver diseases. Eighty of 98 patients who underwent EUS during the 3-month study period met the criteria. Approval for the study was obtained from the Bezmialem Vakif University Medical Faculty Clinical Research Ethics Board (approval no. 71306642-050.01.04). The study was conducted according to the Helsinki Declaration of 1964 and its later amendments and the International Association for the Study of Pain (IASP) guidelines for pain research in animals and humans. The investigators personally and thoroughly informed all participants of the study's aims and structure. Patients were informed that participation was voluntary and anonymous, and would not affect their care. Informed consent for participation in the study was obtained from each patient.

\section{Data Collection}

Patients were instructed to fill out the STAI and PSQ forms that they were given for preoperative assessment before the procedure. Patients received a detailed explanation of each form and completed the forms in a quiet room. The patients were educated on the scoring of the visual analog scale (VAS, 0-10) for postoperative pain evaluation.

\section{Assessment of Anxiety}

Spielberger's STAI used in the measurement of anxiety consists of two parts. State anxiety (STAI-S) assesses the state of anxiety depending on the intensity of the current emotional event affecting anxiety. Trait anxiety (STAI-T) assesses more persistent anxiety, which is stable over time and is not affected by the intensity of momentary emotional states [16]. The STAI has been translated into Turkish and its reliability and validity confirmed by Oner and Le Compte [17].

\section{Assessment of Pain Sensitivity}

The PSQ was developed by Ruscheweyh et al. to assess pain sensitivity [15]. It is a non-invasive, easy, and reliable survey that assesses pain sensitivity by imagining painful situations occurring in everyday life. The PSQ is a selfadministered rating of pain sensitivity and was found to yield results similar to the pain sensitivity assessed by experimental methods [15]. The PSQ is based on the rating of 17 different painful conditions in everyday life on an 11 -point scale $(0=$ no pain; $10=$ the most severe pain). It can be completed within 5-10 min. Three items $(5,9,13)$ describe situations that are not normally considered painful by healthy individuals (for example, taking a hot shower) and are not included in the total score. In addition to the PSQ total score, two other scores, i.e., PSQ minor pain score and PSQ moderate pan score, were also created. These two sub-scores were defined by factor analysis in the previous study [15]. PSQ minor includes seven cases that cause minor pain (mean score of $<4$ on the 11-point scale), and the PSQ moderate includes seven other cases causing moderate pain (mean score of 4-6 on the 11-point scale). The PSQ total score was calculated as the average score of items $1,2,3,4,6,7$, $8,10,11,12,14,15,16$, and 17 (excluding three painless cases). The PSQ minor score was calculated as the average score of items $3,6,7,10$, 11,12 , and 14 , and the PSQ moderate score was calculated as the average score of items $1,2,4$, $8,15,16$, and 17 .

\section{Anesthetic Techniques}

All patients were taken into the procedure room without premedication prior to the procedure. Basal values of heart rate (HR), systolic arterial pressure, diastolic arterial pressure, oxygen saturation $\left(\mathrm{SpO}_{2}\right)$, and respiratory rate were measured in patients who were under standard monitoring. Vascular access was established through a 20-gauge IV catheter.

A bispectral index (BIS; Aspect Medical Systems/Covidien, MA, USA) was used for monitoring to measure the depth of anesthesia [22]. 
During BIS measurements, patients were asked to close their eyes and not to speak or move. Noncommissioned personnel in the procedure room were asked to leave the room, and unnecessary lights were switched off [23].

All patients were given oxygen through a nasal cannula at a dose of $2 \mathrm{~L} \mathrm{~min}^{-1}$ starting from the beginning of sedation. For sedation, $0.03 \mathrm{mg} \mathrm{kg}^{-1}$ midazolam, $1 \mathrm{mg} \mathrm{kg}^{-1}$ lidocaine, $1 \mu \mathrm{kg}^{-1}$ fentanyl, and then a bolus dose of $1 \mathrm{mg} \mathrm{kg}^{-1}$ propofol were administered intravenously using an infusion pump over $60 \mathrm{~s}$. The elapsed time until the BIS value reached 75 was recorded. For maintenance of the anesthesia, $2 \mathrm{mg} \mathrm{kg}^{-1} \mathrm{~h}^{-1}$ propofol infusion was started. Medium-deep sedation was ensured with a BIS value of 65-75 during the procedure [10]. In the case of sedation failure, an additional dose of $0.1 \mathrm{mg} \mathrm{kg}^{-1}$ of propofol (IV) was administered, and the propofol infusion was halted once the BIS value dropped below 65 .

The total duration of the procedure, the total amount of propofol consumed during this time, and the number of additional doses of propofol needed were recorded.

Potential cardiopulmonary conditions and the interventions performed were recorded. Intravenous administration of $0.001 \mathrm{mg} \mathrm{kg}^{-1}$ atropine was planned in the event of bradycardia $\left(\mathrm{HR}<50 \mathrm{~min}^{-1}\right)$, while reduction of propofol dosage, $0.9 \%$ isotonic fluid loading, and intravenous administration of $5 \mathrm{mg}$ ephedrine as needed were planned in the case of hypotension (systolic arterial pressure $<80 \mathrm{mmHg}$ ), and increasing oxygen flow, lifting the jaw, discontinuation of propofol, stopping the procedure, and implementing mask ventilation if necessary were planned in the event of hypoxia $\left(\mathrm{SpO}_{2}<90 \%\right)$ development.

The patients were taken to the recovery unit for monitoring once their hemodynamics were appropriate following the completion of the procedure. Eligibility for transfer from the recovery room to the service was assessed using the Aldrete recovery score (ARS). The duration of stay in the recovery room until reaching an ARS score of 9 was recorded; patients with an ARS score of 9 were sent to their services. The numeric rating scale was used for postoperative nausea and vomiting, while the visual analog scale (VAS, 0-10) was used for postoperative pain assessment. VAS was assessed at $1 \mathrm{~h}$ and $2 \mathrm{~h}$. In the case of a VAS value of $\geq 4,20 \mathrm{mg}$ $\mathrm{kg}^{-1}$ paracetamol was administered intravenously. All data were recorded.

Intraoperative and postoperative parameters were assessed by an independent anesthesiologist who was blinded to the assessment of preoperative anxiety and pain sensitivity.

\section{Statistical Analysis}

The Statistical Package for the Social Sciences version 22.0 (IBM Corporation, Armonk, NY, USA) program was used for the statistical analysis. Descriptive values of the obtained data were calculated as mean $\pm \mathrm{SD}$, number, and frequency in percentage. The independentsamples $t$-test was used to compare the two sexes in terms of STAI-S, STAI-T, PSQ minor, PSQ moderate, and PSQ total scores. Relations between preoperative anxiety and pain sensitivity levels and other numerical clinical and sociodemographic characteristics were examined using Pearson's correlation analysis. A value of $p<0.05$ was considered as indicating statistical significance.

The sample size was calculated using simple random sampling from the study population, which identified a total of 98 patients, and the required values were substituted in the formula and yielded a minimum number of 78 patients for adequate statistical power $\left[n=(98)(1.96)^{2}(0.5)(0.5) /\right.$

$\left.(0.05)^{2}(98-1)+(1.96)^{2}(0.5)(0.5)\right] \quad(p=0.5 \quad$ is considered).

\section{RESULTS}

A total of 80 patients who underwent EUS successfully completed the STAI and PSQ forms. The demographic data and preoperative information of the patients are given in Tables 1 and 2.

The STAI-S, STAI-T, PSQ minor, and PSQ total scores did not differ significantly between the two sexes (Table 3). A significant positive correlation was found between the STAI-S and 
Table 1 Demographic data of the patients $(n=80)$

\begin{tabular}{ll}
\hline & $n(\%)$ \\
\hline Gender & $37(46.3)$ \\
Female & $43(53.8)$ \\
ASA & \\
1 & $36(45.0)$ \\
2 & $44(55.0)$ \\
Diagnosis & \\
Pancreatic cancer & $23(28.7)$ \\
Submucosal lesion & $14(17.5)$ \\
Esophageal lesion & $7(8.8)$ \\
Pancreatic cyst & $9(11.3)$ \\
Chronic pancreatitis & $6(7.5)$ \\
Mass in the portal area & $4(5.0)$ \\
Mass in the pancreas & $7(8.8)$ \\
Choledocholithiasis & $5(6.3)$ \\
Others & $5(6.3)$ \\
\hline
\end{tabular}

Percentages and absolute values are given.

ASA American Society of Anesthesiologists

STAI-T scores and the PSQ minor, PSQ moderate, and PSQ total scores (Table 4).

Hypotension as a cardiopulmonary complication was observed in only one patient. The propofol dose was reduced and fluid was administered intravenously for treatment. Bradycardia was observed in two patients and was corrected by intravenous administration of $0.001 \mathrm{mg} \mathrm{kg}^{-1}$ atropine. None of the patients needed ventilation support during the study period.

The time to reach BIS of 75 , propofol infusion dose used during sedation, the need for additional doses of propofol, and the duration of post-anesthesia care unit (PACU) stay were found to be significantly positively correlated with both preoperative anxiety and preoperative pain sensitivity. In other words, as the STAI$\mathrm{T}$, STAI-S, and PSQ scores increased, significant
Table 2 Perioperative data of the patients

\begin{tabular}{ll}
\hline & $\begin{array}{l}n=80 \\
\text { Mean (SD) [range] }\end{array}$ \\
\cline { 1 - 2 } Age (years) & $53.79(9.99)[23-76]$ \\
Weight (kg) & $75.63(13.66)[44-103]$ \\
Height (cm) & $166.18(8.48)[150-186]$ \\
Anesthesia duration (min) & $19.30(8.18)[5-45]$ \\
PACU duration (min) & $11.05(7.18)[1-27]$ \\
Time to reach BIS:75 (s) & $59.20(30.93)[10-184]$ \\
Number of additional doses & $47.54(23.97)[4.0-108.0]$ \\
Propofol dose (mg kg $\left.{ }^{-1} \mathrm{~h}^{-1}\right)$ & $5.84(2.76)[0.84-14.02]$ \\
\hline Data were calculated as mean (SD), number, and frequency \\
in percentage \\
PACU post-anesthesia care unit, BIS bispectral index
\end{tabular}

Table 3 Comparison of STAI-S, STAI-T, and PSQ values by sex

\begin{tabular}{lllrrl}
\hline & Sex & $\boldsymbol{n}$ & Mean & \multicolumn{1}{l}{ SD } & \multicolumn{1}{l}{$\boldsymbol{P}$} \\
\hline STAI-S & M & 37 & 44.11 & 11.918 & 0.185 \\
& F & 43 & 47.53 & 10.820 & \\
STAI-T & M & 37 & 37.05 & 9.638 & 0.242 \\
& F & 43 & 39.63 & 9.825 & \\
PSQ minor & M & 37 & 4.11 & 1.561 & 0.434 \\
& F & 43 & 4.37 & 1.455 & \\
PSQ moderate & M & 37 & 5.31 & 1.82 & 0.285 \\
& F & 43 & 5.74 & 1.72 & \\
PSQ total & M & 37 & 4.93 & 1.697 & 0.289 \\
& F & 43 & 5.33 & 1.637 & \\
\hline
\end{tabular}

The independent samples $t$-test was used.

STAI-S state anxiety, STAI-T trait anxiety, PSQ Pain Sensitivity Questionnaire

increases were observed in the values of these parameters (Table 5). In terms of hemodynamic parameters, systolic arterial pressure was positively correlated only with pain sensitivity, 
Table 4 Relation between STAI-T, STAI-S, and PSQ

\begin{tabular}{|c|c|c|c|c|c|c|c|c|}
\hline \multirow[t]{2}{*}{$n=80$} & \multicolumn{2}{|c|}{ PSQ minor } & \multicolumn{2}{|c|}{ PSQ moderate } & \multicolumn{2}{|c|}{ PSQ total } & \multicolumn{2}{|l|}{ STAI-T } \\
\hline & $r$ & $p$ & $r$ & $p$ & $r$ & $p$ & $r$ & $p$ \\
\hline STAI-S & $0.621^{* *}$ & 0.001 & 0.563 & 0.001 & $0.653^{* *}$ & 0.001 & $0.826^{* *}$ & 0.001 \\
\hline STAI-T & $0.537^{* *}$ & 0.001 & 0.485 & 0.001 & $0.570^{* *}$ & 0.001 & - & - \\
\hline
\end{tabular}

Bold indicates the significant difference at $p<0.01$

Pearson correlation analysis was used

STAI-S state anxiety, STAI-T trait anxiety, PSQ Pain Sensitivity Questionnaire

Pearson correlation $(r)$ 0.00-0.19 "very weak;" 0.20-0.39 “weak;" 0.40-0.59 “moderate;" 0.60-0.79 "strong;" 0.80-1.0 "very strong"

$n=80$.

${ }^{* *} p<0.01$

while HR was correlated with anxiety and pain sensitivity (Table 5). The respiratory rate was positively correlated only with pain sensitivity (Table 5). In terms of postoperative pain, VAS $1 \mathrm{~h}$ was found to be correlated with STAI-S, STAI-T, and PSQ (Table 5). VAS $2 \mathrm{~h}$ was only correlated with STAI-S and STAI-T (Table 5).

\section{DISCUSSION}

In the present study, preoperative anxiety and pain sensitivity were found to be correlated with the time elapsed until reaching the desired sedation level, the need for preoperative propofol administration, postoperative recovery time, and postoperative pain intensity.

Anxiety is an unpleasant emotional condition. State anxiety is defined as subjective emotions such as anxiety, nervousness, and tension which are felt when exposed to an anxiety-triggering stimulus. Trait anxiety is defined as a constant tendency to experience stress on a daily basis. It has already been shown that the state anxiety also rises in a state that stimulates anxiety in people with high persistent anxiety [10]. In the current study, the state anxiety and the trait anxiety were similarly found to be highly correlated in patients.

Pain is a complex and subjective experience, with physicochemical and emotional components. Pain is specific to each individual and shows a wide range of variation among individuals. Anxiety is reported to be one of the most important psychological determinants of the severity and intensity of pain, which is subjective and individual [24, 25]. It is known that individuals with high anxiety levels experience more intense pain [26]. The present study also observed that anxiety and pain sensitivity are positively correlated.

In order to provide a homogeneous distribution in terms of pain perception scores, we included patients who had an educational level and mental status sufficient to fill out the scales and questionnaires, had no psychiatric or neurological diseases, and were not chronic users of psychiatric drugs or alcohol.

Previous studies have demonstrated contradictory results for the relation between anxiety and anesthetic requirements. Chung et al. measured the depth of anesthesia based on subjective clinical observation, and reported that anxiety and anesthetic consumption were not correlated [41]. There was however a methodological limitation, as it was difficult for the authors to determine the exact consumption of anesthetics using this method. Other clinical trials also addressed this problem using a BIS monitor, but the results were not consistent $[3,9]$. Kil et al. found that propofol need correlated with STAI-S and STAI-T during mild and moderate sedation (BIS: 75-85). However, there was no association between preoperative anxiety and a need for anesthetics (minimum alveolar concentration [MAC]-hour of sevoflurane) reported in this study. Its findings suggest that the effect of anxiety on the need for 
Table 5 Correlation of pain sensitivity with other parameters

\begin{tabular}{|c|c|c|c|c|c|c|c|c|c|c|c|}
\hline & \multirow[b]{2}{*}{$(n)$} & \multicolumn{2}{|c|}{ PSQ minor } & \multicolumn{2}{|c|}{ PSQ moderate } & \multicolumn{2}{|c|}{ PSQ total } & \multicolumn{2}{|l|}{ STAI-S } & \multicolumn{2}{|c|}{ STAI-T } \\
\hline & & $r$ & $p$ & $r$ & $p$ & $r$ & $p$ & $r$ & $p$ & $r$ & $p$ \\
\hline BIS:75 duration & 80 & $0.401^{* *}$ & 0.001 & $0.301^{* *}$ & 0.007 & $0.348^{* *}$ & 0.002 & $0.623^{* *}$ & 0.001 & $0.499^{* *}$ & 0.001 \\
\hline Propofol additional dose & 80 & $0.766^{* *}$ & 0.001 & $0.692^{* *}$ & 0.001 & $0.761^{* *}$ & 0.001 & $0.674^{* *}$ & 0.001 & $0.612^{* *}$ & 0.001 \\
\hline Propofol infusion & 80 & $0.781^{* *}$ & 0.001 & $0.724^{* *}$ & 0.001 & $0.808^{* *}$ & 0.001 & $0.731^{* *}$ & 0.001 & $0.597^{* *}$ & 0.001 \\
\hline $\mathrm{HR}$ & 80 & $0.289^{* *}$ & 0.009 & $0.348^{* *}$ & 0.002 & $0.335^{* *}$ & 0.002 & $0.286^{*}$ & 0.010 & $0.221^{*}$ & 0.048 \\
\hline SAP & 80 & $0.221^{*}$ & 0.049 & $0.246^{*}$ & 0.028 & $0.243^{*}$ & 0.030 & 0.169 & 0.134 & 0.090 & 0.428 \\
\hline DAP & 80 & 0.090 & 0.425 & 0.171 & 0.129 & 0.134 & 0.235 & 0.024 & 0.836 & 0.002 & 0.987 \\
\hline MAP & 80 & 0.151 & 0.182 & $0.225^{*}$ & 0.045 & 0.197 & 0.080 & 0.082 & 0.468 & 0.062 & 0.583 \\
\hline Respiratory rate & 80 & $0.276^{*}$ & 0.013 & $0.387^{* *}$ & 0.001 & $0.326^{* *}$ & 0.003 & 0.165 & 0.143 & 0.074 & 0.515 \\
\hline PACU duration & 80 & $0.640^{* *}$ & 0.001 & $0.504^{* *}$ & 0.001 & $0.627^{* *}$ & 0.001 & $0.599^{* *}$ & 0.001 & $0.509^{* *}$ & 0.001 \\
\hline VAS $1 \mathrm{~h}$ & 80 & $0.236^{*}$ & 0.035 & $0.226^{*}$ & 0.044 & $0.265^{*}$ & 0.018 & $0.337^{* *}$ & 0.002 & $0.388^{* *}$ & 0.001 \\
\hline VAS $2 \mathrm{~h}$ & 80 & 0.189 & 0.094 & $0.222^{*}$ & 0.248 & 0.216 & 0.055 & $0.250^{*}$ & 0.026 & $0.273^{*}$ & 0.014 \\
\hline
\end{tabular}

Bold indicates the significant difference $p<0.01, p<0.05$

$H R$ heart rate, $S A P$ systolic arterial pressure, $D A P$ diastolic arterial pressure, MAP mean arterial pressure, $P A C U$ postanesthesia care unit, BIS bispectral index, VAS visual analog scale, STAI-S state anxiety, STAI-T trait anxiety, PSQ Pain Sensitivity Questionnaire

Pearson correlation analysis was used

Pearson correlation $(r) \quad 0.00-0.19=$ very weak; $0.20-0.39=$ weak; $0.40-0.59=$ moderate; $0.60-0.79=$ strong; $0.80-$ $1.0=$ very strong

$n=80$

${ }^{* *} p<0.01,{ }^{*} p<0.05$

anesthetics may be less when the depth of sedation is greater [10]. On the other hand, Gurbulak et al. observed that elevated anxiety levels were associated with increased drug doses required for sedation [27]. The inconsistency between these results may be due to methodological differences and the depth of anesthesia. In the present study, high preoperative sensitivity and pain sensitivity were found to correlate with increased consumption of propofol and the time to reach the desired sedation level. This result can be attributed to our monitoring of sedation depth and standardizing the BIS value to $65-75$. Studies have also found that neuroendocrine responses are increased more dramatically in people with high anxiety levels, reporting increased cardiovascular activity in such individuals $[2,3,16]$. As reported in the present study, increased basal hemodynamics can be an important cause of higher anesthetic consumption in patients with high anxiety.

The prolongation of PACU stay, which is an indicator of postoperative recovery, may also be associated with increased use of propofol in patients with high anxiety and pain sensitivity.

Anxiety is associated with low pain threshold, exaggerated pain intensity, and activation of hippocampal formation [29-31]. Although psychological factors are known to be associated with pain, contradictory results have been observed. For example, in some studies, postoperative pain is positively correlated with both state anxiety and trait anxiety [9], while in other studies it is correlated only with state anxiety $[13,32,33]$. In another study, there was no significant correlation between postoperative pain and anxiety [34]. These differences may be due to the measurement surveys, types of surgery, and sample sizes. 
Previous studies have already shown that experimental preoperative pain sensitivity assessments can be used to estimate the severity of acute postoperative pain [35-37]. Among experimental pain intensity assessment methods, PSQ is advantageous, as it is fast, painless, and easy to apply. Rehberg et al. investigated the effects of PSQ and the experimental parameters of pain sensitivity on postoperative pain. They reported that the intensity of acute postoperative pain was positively correlated with PSQ [5]. Kim et al. also reported that, compared to patients with lower pain sensitivity of back pain, leg pain, and disability pain, patients with higher preoperative pain sensitivity had poorer recovery at the end of the first 12-month postoperative period after spinal stenosis surgery [38]. Valeberg et al. found that PSQ correlated positively with postoperative pain intensity in patients under the age of 70 [12].

Another study reported that, compared to anxiety, pain sensitivity is a better predictor of postoperative pain [10]. In postoperative pain, anxiety was reported to exert more profound effects during the immediate postoperative period, while pain sensitivity was found to have a higher correlation with the long-term (24-48 h) results [10].

In the present study, postoperative pain was significantly positively correlated with both factors at VAS $1 \mathrm{~h}$, while it was significantly positively correlated only with anxiety at VAS $2 \mathrm{~h}$. EUS, which is the procedure that this study group underwent, is a preoperatively painful procedure, but postoperative pain varies depending on the procedure performed. Postoperative pain is often not experienced to a significant degree in EUS, especially when performed for diagnostic purposes. Therefore, we are of the opinion that the pain sensitivity of the patient group is not sufficient to assess its relation with postoperative pain.

High levels of anxiety increase the secretion of catecholamines, and catecholamines cause tachycardia, hypertension, and arrhythmia. Increased cortisol secretion results in the activation of the hypothalamus-pituitary-adrenal axis [39-41]. In these patients, hemodynamic changes (tachycardia, hypertension, arrhythmia) are observed more frequently [7]. In a study by Kil et al., arterial pressure, but not HR, was correlated with anxiety [10]. Noto et al. showed that state anxiety and HR increased with mental arithmetic stress [40]. Chung et al. did not find a relationship between anxiety and hemodynamic values [41]. These contradictory results may be due to differences in patient groups and timing, the methods for assessment of variables, and types of stress. The small sample sizes may also be responsible for these differences. In the present study, the basal HR value was correlated with anxiety and pain sensitivity, but this correlation was positive only with pain sensitivity. We could explain this situation better if we could have measured the neuroendocrine response as an objective measurement. This is a limitation of the present study.

The other limitation of the current study is that the methods used herein are mostly based on patients' subjective scores on a self-administered rating scale rather than objective indicators of pain and anxiety.

\section{CONCLUSIONS}

The presence of a significant linear correlation between preoperative anxiety and pain sensitivity and anesthesia need can be used to predict an individual patient's anesthetic consumption, thereby facilitating better preoperative management. Compared to experimental pain intensity assessment methods, the PSQ is advantageous for current use, as it is quick, painless, and easy to apply. The present study contributes to the literature by further supporting the validity of preoperative anxiety and pain sensitivity assessment for predicting the need for preoperative anesthetics.

\section{ACKNOWLEDGEMENTS}

We thank the participants of the study.

Funding. The journal's Rapid Service Fee was funded by the authors. 
Authorship. All named authors meet the International Committee of Medical Journal Editors (ICMJE) criteria for authorship for this article, take responsibility for the integrity of the work as a whole, and have given their approval for this version to be published.

Authors' Contributions. All authors contributed to the study's conception and design. Material preparation and data collection were performed by Ferda Yilmaz Inal, Hayrettin Daskaya. Yadigar Yilmaz Camgoz, Hasan Kocoglu performed the analyses and wrote the first draft of the manuscript; all authors commented on previous versions of the manuscript. All authors read and approved the final manuscript.

Prior Presentation. This study was orally presented at the 51st National Turkish Anesthesiology and Reanimation Congress, Antalya, Turkey.

Disclosures. All authors (Ferda Yilmaz Inal, Yadigar Yilmaz Camgoz, Hayrettin Daskaya. Hasan Kocoglu) have nothing to disclose.

Compliance with Ethics Guidelines. Approval No. 71306642-050.01.04 was obtained from Bezmialem Vakif University Medical Faculty Clinical Research Ethics Board for the study. The study was conducted according to the Helsinki Declaration of 1964 and its later amendments and IASP's guidelines for pain research in animals and humans. The investigators informed all participants on the study's aims and structure. Patients were informed that participation was voluntary, anonymous, and would not affect their care; hence, informed consent for participating in the study was obtained from each patient.

Data Availability. The datasets generated during and/or analyzed during the current study are available from the corresponding author on reasonable request.

Open Access. This article is licensed under a Creative Commons Attribution-NonCommercial 4.0 International License, which permits any non-commercial use, sharing, adaptation, distribution and reproduction in any medium or format, as long as you give appropriate credit to the original author(s) and the source, provide a link to the Creative Commons licence, and indicate if changes were made. The images or other third party material in this article are included in the article's Creative Commons licence, unless indicated otherwise in a credit line to the material. If material is not included in the article's Creative Commons licence and your intended use is not permitted by statutory regulation or exceeds the permitted use, you will need to obtain permission directly from the copyright holder. To view a copy of this licence, visit http://creativecommons.org/licenses/by$\mathrm{nc} / 4.0 /$.

\section{REFERENCES}

1. Turk DC, Okifuji A. Assessment of patients' reporting of pain: an integrated perspective. Lancet. 1999;353:1784-8.

2. Bisgaard T, Klarskov B, Rosenberg J, Kehlet $\mathrm{H}$. Characteristics and prediction of early pain after laparoscopic cholecystectomy. Pain. 2001;90: 261-9.

3. Osborn TM, Sandler NA. The effects of preoperative anxiety on intravenous sedation. Anesth Prog. 2004;51:46-51.

4. Pan PH, Coghill R, Houle TT, et al. Multifactorial preoperative predictors for postcesarean section pain and analgesic requirement. Anesthesiology. 2006;104:417-25.

5. Rehberg B, Mathivon S, Combescure C, Mercier Y, Savoldelli GL. Prediction of acute postoperative pain following breast cancer surgery using the pain sensitivity questionnaire: a Cohort Study. Clin J Pain. 2017;33(1):57-66.

6. Munafò MR, Stevenson J. Anxiety and surgical recovery. Reinterpreting the literature. J Psychosom Res. 2001;51:589-96.

7. Kim WS, Byeon GJ, Song BJ, Lee HJ. Availability of preoperative anxiety scale as a predictive factor for hemodynamic changes during induction of anesthesia. Korean J Anesthesiol. 2010;58:328-33. 
8. Salmon P, Kaufman L. Preoperative anxiety and endocrine response to surgery. Lancet. 1990;335: 1340 .

9. Maranets I, Kain ZN. Preoperative anxiety and intraoperative anesthetic requirements. Anesth Analg. 1999;89:1346-51.

10. Kil HK, Kim WO, Chung WY, Kim GH, Seo H, Hong JY. Preoperative anxiety and pain sensitivity are independent predictors of propofol and sevoflurane requirements in general anaesthesia. Br J Anaesth. 2012;108:119-25.

11. Kim H-J, Park J-H, Kim J-W, et al. Prediction of postoperative pain intensity after lumbar spinal surgery using pain sensitivity and preoperative back pain severity. Pain Med. 2014;15:2037-45.

12. Valeberg BT, Høvik LH, Gjeilo KH. Relationship between self-reported pain sensitivity and pain after total knee arthroplasty: a prospective study of 71 patients 8 weeks after a standardized fast-track program. J Pain Res. 2016;9:625-9.

13. Granot M. Can we predict persistent postoperative pain by testing preoperative experimental pain? Curr Opin Anaesthesiol. 2009;22:425-30.

14. Bachiocco V, Morselli AM, Carli G. Self-control expectancy and postsurgical pain: relationships to previous pain, behavior in past pain, familial pain tolerance models, and personality. J Pain Symptom Manage. 1993;8:205-14.

15. Ruscheweyh R, Marziniak M, Stumpenhorst F, Reinholz J, Knecht S. Pain sensitivity can be assessed by self-rating: development and validation of the Pain Sensitivity Questionnaire. Pain. 2009;146: 65-74.

16. Spielberger CD. Manual for the State-Trait Anxiety Inventory (STAI: Form Y). Palo AltoA: Consulting Psychologists Press; 1983.

17. Oner N, Le Compte A. Durumluk-Sürekli Kayg1 Envanteri El kitabı.İstanbul: Boğaziçi Yayınları, 1985.

18. Rizzo J, Bernstein D, Gress F. A randomized doubleblind placebo-controlled trial evaluating the costeffectiveness of droperidol as a sedative premedication for EUS. Gastrointest Endosc. 1999;50: 178-82.

19. Yusoff IF, Raymond G, Sahai AV. Endoscopist administered propofol for upper-GI EUS is safe and effective: a prospective study in 500 patients. Gastrointest Endosc. 2004;60:356-60.

20. Allescher HD, Roesch T, Willkomm G, Lorenz R, Meining A, Classen M. Performance, patient acceptance, appropriateness of indications and potential influence on outcome of EUS: a prospective study in 397 consecutive patients. Gastrointest Endosc. 1999;50:737-45.

21. Bonta PI, Kok MF, Bergman JJ, Van den Brink GR, Lemkes JJ, Tytgat GN, et al. Conscious sedation for EUS of the esophagus and stomach: a double-blind, randomized, controlled trial comparing midazolam with placebo. Gastrointest Endosc. 2003;57:842-7.

22. Glass PS, Bloom M, Kearse L, Rosow C, Sebel P, Manberg P. Bispectral analysis measures sedation and memory effects of propofol, midazolam, isoflurane, and alfentanil in healthy volunteers. Anesthesiology. 1997;86:836-47.

23. Kim DW, Kil HY, White PF. The effect of noise on the bispectral index during propofol sedation. Anesth Analg. 2001;93:1170-3.

24. Vaajoki A, Pietilä AM, Kankkunen P, et al. Effects of listening to music on pain intensity and pain distress after surgery: an intervention. J Clin Nurs. 2012;21:708-17 ([CrossRef]).

25. Rosén IH, Bergh HI, Odén A, et al. Patients' experiences of pain following day surgery-at 48 hours, seven days and three months. Open Nurs J. 2011;5: $52-9$.

26. Dedeli Ö, Fadıloğlu Ç, Uyar M. Kronik nonmalign ağrısı olan bireylerde bilişsel-davranışçı ağrı modeli'nin incelenmesi. MN Dahili Tıp Bilimleri Dergisi. 2008;3:232-42.

27. Gürbulak B, Üçüncü MZ, Yardımcı E, Kırlı E, Tüzüner F. Impact of anxiety on sedative medication dosage in patients undergoing esophagogastroduodenoscopy. Wideochir Inne Tech Maloinwazyjne. 2018;13(2):192-8.

28. Wong PS. Anxiety, signal anxiety, and unconscious anticipation: neuroscientific evidence for an unconscious signal function in humans. Am Psychoanal Assoc. 1999;47:817-41.

29. Rhudy JL, Meagher MW. Fear and anxiety: divergent effects on human pain thresholds. Pain. 2000;84:65-75.

30. al Absi M, Rokke PD. Can anxiety help us tolerate pain? Pain. 1991;46:43-5129.

31. Scott LE, Clum GA, Peoples JB. Preoperative predictors of postoperative pain. Pain. 1983;15:283-93.

32. Nelson FV, Zimmerman L, Barnason S, Nieveen J, Schmaderer M. The relationship and influence of anxiety on postoperative pain in the coronary artery bypass graft patient. J Pain Symptom Manag. 1998;15:102-9. 
33. Hsu YW, Somma J, Hung YC, Tsai PS, Yang $\mathrm{CH}$, Chen CC. Predicting postoperative pain by preoperative pressure pain assessment. Anesthesiology. 2005;103:613-8.

34. Abrishami A, Chan J, Chung F, et al. Preoperative pain sensitivity and its correlation with postoperative pain and analgesic consumption: a qualitative systematic review. Anesthesiology. 2011;114:445-57.

35. Werner MU, Mjöbo HN, Nielsen PR, et al. Prediction of postoperative pain: a systematic review of predictive experimental pain studies. Anesthesiology. 2010;112:1494-502.

36. Kim H-J, Lee J-I, Kang K-T, et al. Influence of pain sensitivity on surgical outcomes after lumbar spine surgery in patients with lumbar spinal stenosis. Spine. 2015;40(3):193-200.

37. Badner NH, Nielson WR, Munk S, Kwiatkowska C, Gelb AW. Preoperative anxiety detection and contributing factors. Can J Anaesth. 1990;37:444-7.
38. Froehlich F, Harris JK, Wietlisbach V, et al. Current sedation and monitoring practice for colonoscopy: an International Observational Study (EPAGE). Endoscopy. 2006;38:461-9.

39. Wang A, Hoda KM, Holub JL, Eisen GM. Does level of sedation impact detection of advanced neoplasia? Dig Dis Sci. 2010;55:2337-43.

40. Noto Y, Sato T, Kudo M, Kurata K, Hirota K. The relationship between salivary biomarkers and state-trait anxiety inventory score under mental arithmetic stress: a pilot study. Anesth Analg. 2005;101:1873-6.

41. Chung K-C, Juang S-E, Lee K-C, Hu W-H, Lu C-C, Lu $\mathrm{H}-\mathrm{F}$, Hung K-C. The effect of pre-procedure anxiety on sedative requirements for sedation during colonoscopy. Anaesthesia. 2013;68(3):253-9. 